\title{
Wilms tumor, aniridia, genitourinary anomalies, and mental retardation syndrome with deletion of chromosome 11p14.3p12
}

\author{
Go Hun Seo, Yoon-Myung Kim, ${ }^{1, \neq}$, Gu-Hwan Kim², Eul-Ju Seo ${ }^{2}$, Jin Ho Choi', Beom Hee Lee ${ }^{1,2}$, and Han-Wook Yoo ${ }^{1,2, *}$ \\ 'Department of Pediatrics, Asan Medical Center Children's Hospital, University of Ulsan College of Medicine, Seoul, Korea \\ ${ }^{2}$ Medical Genetics Center, Asan Medical Center Children's Hospital, University of Ulsan College of Medicine, Seoul, Korea
}

\begin{abstract}
WAGR (Wilms tumor, aniridia, genitourinary anomalies, and mental retardation) syndrome is a rare contiguous gene deletion syndrome caused by deleting genes including WT1 and PAX6 genes in 11 p13 region, which is characterized by Wilms tumor, aniridia, genitourinary abnormalities, and intellectual disability. We report the clinical and cytogenetic characteristics of one Korean patient with WAGR syndrome. The patient shows bilateral sporadic aniridia and genital anomalies at 2 months of age. A heterozygous $14.5 \mathrm{Mb}$ interstitial deletion of 11p14.3p12 region was detected by array comparative genomic hybridization. At 2 years and 10 months of age, Wilms tumor is found through regularly abdominal ultrasonography and treated by chemotherapy, radiation therapy and surgery.
\end{abstract}

Key words: WAGR syndrome, Aniridia, Wilms tumor.

\section{Introduction}

WAGR (Wilms tumor, aniridia, genitourinary anomalies, and mental retardation) syndrome is a rare contiguous gene deletion syndrome caused by genomic deletion including the WT1 and PAX6 genes at chromosome $11 \mathrm{p} 13$ region and its incidence is estimated at 1:50,000 to 1:100,000 [1-3]. This condition has distinctive features such as Wilms tumor, aniridia, genitourinary abnormalities, and intellectual disability $[1,3]$. Aniridia is almost always present in patients with WAGR syndrome, and only a few cases have been reported having WAGR syndrome without aniridia [3,4]. In general, thirty percent of patients with sporadic aniridia develop Wilms tumor, and some of them are diagnosed as WAGR syndrome in their later lives [5]. Being a rare genetic disorder, only one patient has been described in Korean population [6]. In the current report, we describe the clinical and cytogenetic characteristics of the second Korean patient with 11 p12p14.3 deletion who has the general characteristic features of WAGR syndrome.

\section{Case}

The patient was the first baby of the non-consanguineous Korean parents. He was born after 38 gestational weeks with a birth weight of 2,800 $\mathrm{g}$ (standard deviation [SD], -1.8). Pregnancy, labor, and vaginal delivery were uneventful. His facial

\footnotetext{
Received: February 27 2018, Revised: April 9 2018, Accepted: April 11 2018, Published: 30 June 2018

${ }^{*}$ Corresponding author: Han-Wook Yoo, M.D., Ph.D. (iD http://orcid.org/0000-0001-8615-186X

Department of Pediatrics, Asan Medical Center Children's Hospital, University of Ulsan College of Medicine, 88 Olympic-ro 43-gil, Songpa-gu, Seoul 05505, Korea.

Tel: +82-2-3010-3374, Fax: +82-2-473-3725, E-mail: hwyoo@amc.seoul.kr

${ }^{\ddagger}$ Current affiliation:Department of Pediatrics, Jeju National University School of Medicine, Jeju, Korea.

Conflict of interest: The authors declare that they do not have any conflicts of interest.

(c) This is an open-access article distributed under the terms of the Creative Commons Attribution Non-Commercial License (http://creativecommons.org/licenses/by-nc/4.0/) which permits unrestricted non-commercial use, distribution, and reproduction in any medium, provided the original work is properly cited.

(c) Copyright 2018 by the Korean Society of Medical Genetics and Genomics 
features were not dysmorphic. At 1 month of age, bilateral cryptorchidism and penoscrotal type hypospadias were found. Right testis was shown in the right inguinal ring on ultrasonography (US), but left testis was invisible. His right cryptorchidism surgically corrected at 2 months of age. At 2 months of age, ophthalmologic examination was done, which revealed bilateral aniridias and cataracts (Fig. 1). Small atrial septal defect was also found on echocardiography. Brain magnetic resonance imaging and auditory evoked potential were normal.

At 3 months of age, his karyotyping was done, which revealed that he had an inversion at chromosome 3 and a deletion at chromosome 11, 46,XY,inv(3)(q13.2q21),del(11)(p11.2p13) (Fig. 2A). His father carried the inversion at chromosome 3, $46, X Y$, inv(3)(q13.2q21), and mother had a normal female karyotype, 46,XX. Multiplex ligation-dependent probe amplification analysis revealed that the patient had whole genomic deletion of the $D C D C 1$ and $P A X 6$ genes on the $11 \mathrm{p} 13$ region and FSHB on the 11 p14.1 region (Fig. 2B). To delineate the interstitial deletion size in chromosome, array comparative genomic hybridization (CGH) performed using the Sureprint G3 Human CGH Microarray 180K kit (Agilent Technologies, Inc., Santa Clara, CA, USA). A heterozygous $14.5 \mathrm{Mb}$ interstitial deletion of $11 \mathrm{p} 14.3 \mathrm{p} 12$ (22004830_36501579, GRCH38) region containing 68 genes was detected (Fig. 2C). ANO5, ANO3, BDNF, CCDC34, KCNA4, FSHB, ELP4, PAX 6, ELP4, WT1, CD59, LMO2, CAT, PDHX, CD44, $S L C 1 A 2, P R R G 4, T R I M 44$, and RAG2 genes have been identified in human disorders (https://www.omim.org/). Thus, he

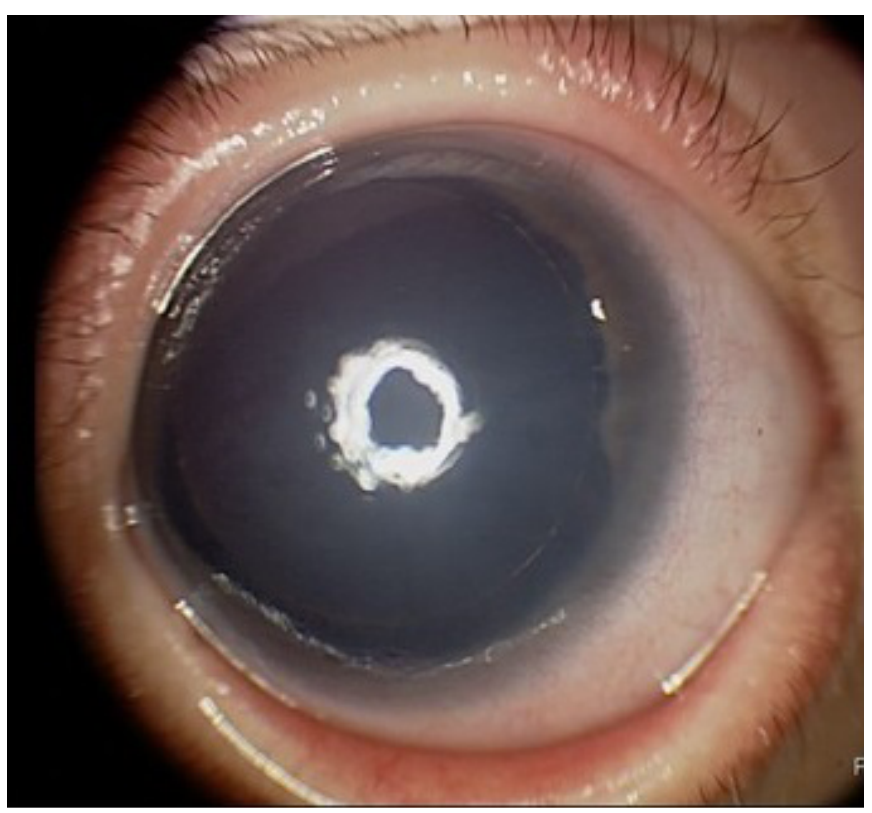

Fig. 1. Aniridia and cataract were noted in both eyes. diagnosed with WAGR syndrome caused by deletions of 11 p12p14.3 chromosome region including PAX6 and WT1 genes.

As both corneal opacities were aggravated, both trabeculectomies were performed at age of 6 months. Urethroplasty for penoscrotal type hypospadias was performed at 1 year of age. Tiny cyst $(0.8 \mathrm{~cm})$ in upper pole of left kidney was found on kidney US at 2 years of age. At 3 years of age, follow-up kidney US showed about $10.6 \times 9.2 \mathrm{~cm}$ sized solid mass in left kidney. Abdominal computed tomography (CT) showed about $10.8 \times 8.2 \times 1$ $0.5 \mathrm{~cm}$ sized well-demarcated heterogeneously enhancing mass arising from upper pole of left kidney, which suggested Wilms tumor (Fig. 3A). His left kidney was radically removed (Fig. 3B), and histological evaluation revealed the triphasic type of Wilms tumor. A fusion whole-body positron emission tomography CT, bone scan, and chest CT scan showed no evidence of distant metastasis. Afterwards he was treated by chemotherapy and radiation therapy. The Korean Infant and Child Development Test was performed at age 1 year and 6 months, which suggested the profound global delay indicative of the development of 6 to 8 months of age. At the latest evaluation of age of 4 years, his height was $97.1 \mathrm{~cm}(-1.3 \mathrm{SD})$, and body weight was $15.5 \mathrm{~kg}$ (-0.6 SD) with 16.4 (0.6 SD) of body mass index $\left(\mathrm{BMI}, \mathrm{kg} / \mathrm{m}^{2}\right)$. His creatinine and blood urea nitrogen level was $0.36 \mathrm{mg} / \mathrm{dL}$ (reference, $0.7-1.4 \mathrm{mg} / \mathrm{dL}$ ) and $17 \mathrm{mg} / \mathrm{dL}$ (reference, $10-26 \mathrm{mg} / \mathrm{dL}$ ), respectively. Scrotal US showed no evidence of gonadoblastoma. Global developmental delay was persistently noted. Abdominal and chest CT scan showed no evidence of recurrence and metastasis. On ophthalmologic examination, he showed good central fixation, visual following in spite of diffuse cornea opacity in both eyes.

\section{Discussion}

Combination of Wilms tumor with aniridia, and other anomalies was firstly described by Miller et al. [1] in 1963. Most common feature in patients with WAGR syndrome is aniridia, followed by genitourinary anomalies, intellectual disability, and Wilms tumor [3]. In addition, cataract, nystagmus, glaucoma, renal dysfunction, behavioral problems, recurrent otitis media, and obesity have been reported in previous studies $[3,4,7]$. Most patients with WAGR syndrome firstly present with sporadic aniridia at newborn period [3]. Importantly, these patients who have sporadic aniridia at infant period have an increased risk of developing Wilms tumor irrespective of presence of WAGR syndrome [5]. Wilms tumor is diagnosed in $80 \%$ of patients with sporadic aniridia before 5 years of age $[2,3]$. Thus, all infant with 
A

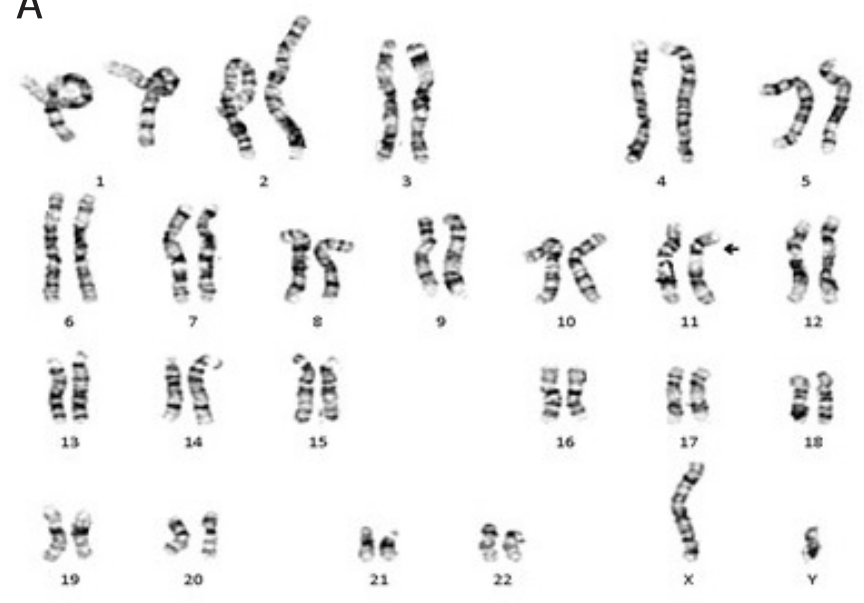

B

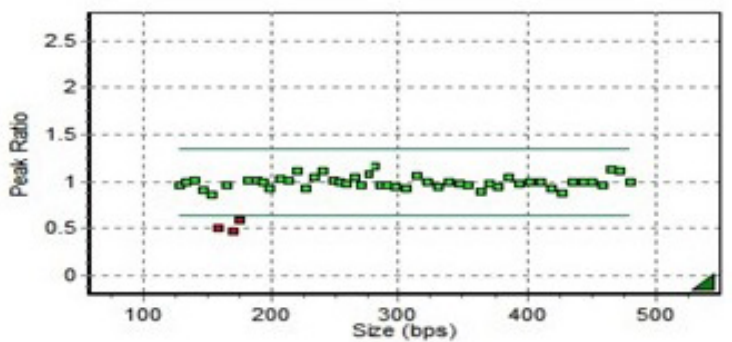

C

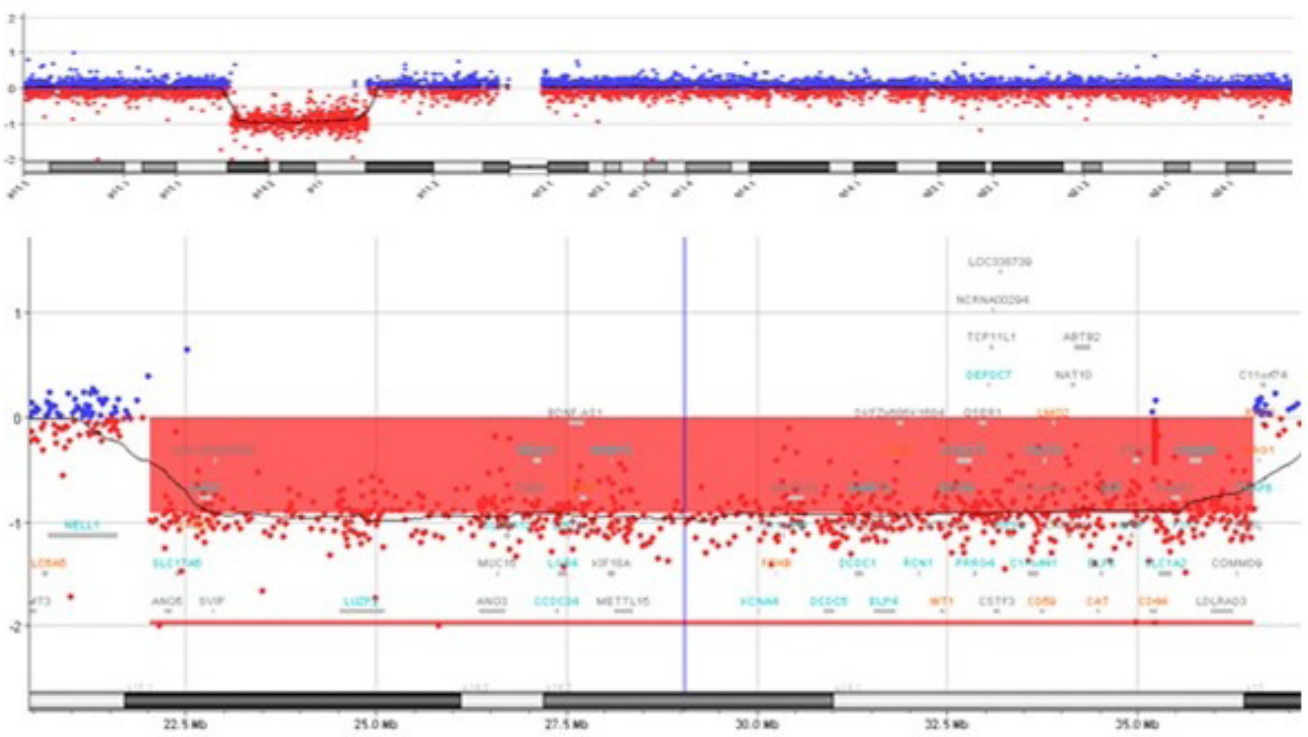

Fig. 2. The results of karyotyping, multiplex ligation-dependent probe amplification (MLPA), and array-comparative genomic hybridization (CGH) analysis. (A) Chromosome analysis was performed using patient's leukocytes in metaphase by conventional G-banded techniques at the level of 550 bands. Karyotype is 46,XY,inv(3)(q13.2q21),del(11)(p11.2p13). (B) The results of MLPA analysis. Green dots indicate normal allele, while red dots are abnormal that is deleted. MLPA analyses were done using two types of SALSA Reference Kit (P064-C1; MRC Holland, Amsterdam, The Netherlands) according to manufacturer's instructions. Red dots are DCDC1, PAX6, and FSHB. (C) Array-CGH data of chromosome 11 and enlargement of the deleted segment. The $14.5 \mathrm{Mb}$ deletion at 11p14.3p12 [(22004830_36501579)×1, GRCH38] is detected.

sporadic aniridia should be evaluated for abdominal mass every 3 to 6 months until 5 years of age [3]. In addition, there is later risk of end stage renal disease associated with Wilms tumor and gonadoblastoma $[3,8]$. Our case initially showed bilateral sporadic aniridia and genital anomalies such as hypospadias and cryptorchidism at infancy. He was subsequently diagnosed with WAGR syndrome at 3 months of age, which warranted the surveillance Wilms tumor since infantile period. He also should observe regularly screening for gonadoblastoma and renal function.

Wilms tumor/genitourinary anomalies and ocular problems are caused by deletion of WT1 and PAX6 gene, respectively $[2,9,10]$. WT1 gene is a tumor suppressor gene involved in development of Wilms tumor as well as genital development $[2,9]$. Its expression is variable among tissues, and WT1 is highly expressed in kidney glomeruli and gonads such as Sertoli cells 
A

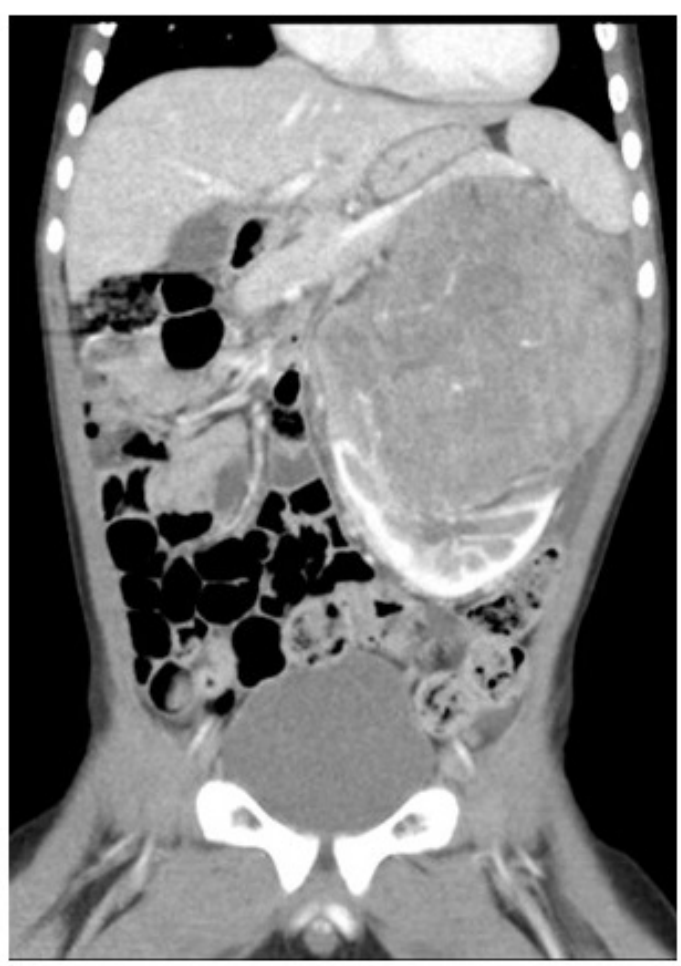

B

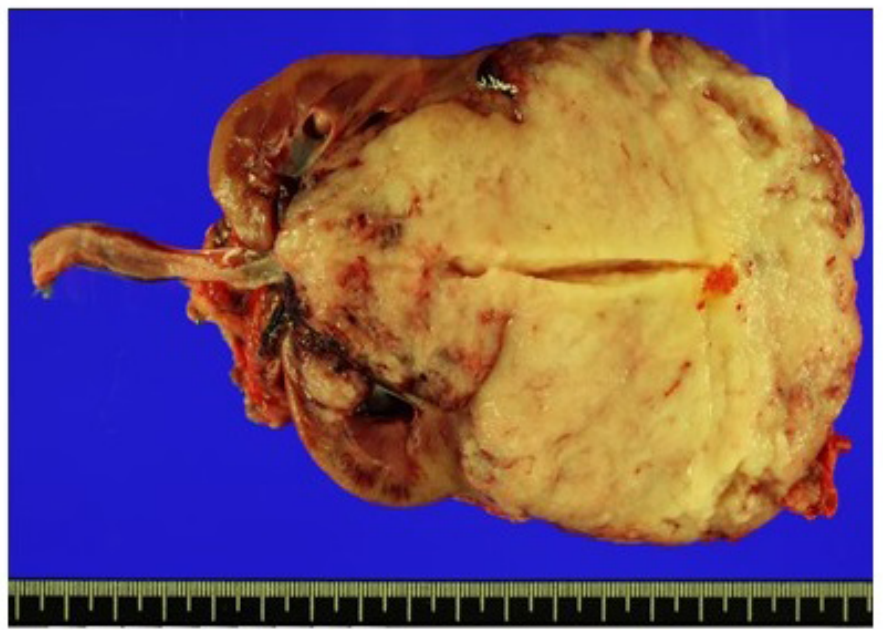

Fig. 3. (A) Abdominal computed tomography reveals $10.8 \times 8.2 \times 10.5 \mathrm{~cm}$ sized well-demarcated heterogeneously enhancing mass originating from left kidney. (B) Gross appearance of left mass after radical nephrectomy reveals $11.1 \times 9.8 \times 7.8 \mathrm{~cm}$ sized with yellowish color.

of testes, epithelial cells and granulosa cells of ovaries [11]. PAX6 gene is expressed in the embryo and involved in the formation of the iris and other ocular structures [12]. Haploinsufficiency of PAX6 gene affects during the development of the eye, which may compromise global impairment of eye morphology. As a result, $P A X 6$ gene mutation generates not only aniridia but also other ocular anomalies such as anterior segment dysgenesis, microphthalmos, corneal dystrophy, nystagmus, cataract, and foveal hypoplasia $[10,13]$. This patient exhibited the typical features of WAGR syndrome including bilateral aniridia, cataract, Wilms tumor, penoscrotal type hypospadias, and cryptorchidism caused by WT1 and PAX6 gene.

There are variable degrees of developmental delay/intellectual disability in WAGR syndrome from normal intelligence in a few patients to severe mental retardation in the majority of the patients [3]. SLC1A2 gene and PRRG4 gene in 11 p13 region and $B D N F$ gene in distal part of 11 p14.1 region are suggested as contributing to intellectual disability and autism as these genes are involved in regulation of neuronal transmitter, cellular function and brain development [7]. Additionally, BDNF gene positioned about $4 \mathrm{Mb}$ telomeric to the WT1 and PAX 6 is also involved in the childhood-onset obesity [14]. Although this patient identified 11p13-p14.3 deletion is non-obese at final visit, regular monitoring for $\mathrm{BMI}$ is necessary for prevention of early onset obesity.

As the second case report of WAGR syndrome in Korean population, our experience helps the pediatricians, oncologists, ophthalmologists, and medical geneticists to identify more cases affected by this condition. As a condition affecting multisystems, multidisciplinary approach is very important to improve the patient clinical outcome.

\section{References}

1. Miller RW, Fraumeni JF Jr, Manning MD. Association of wilms's tumor with aniridia, hemihypertrophy and other congenital malformations. N Engl J Med 1964;270:922-7.

2. Rose $E A$, Glaser $T$, Jones $C$, Smith $C L$, Lewis $W H$, Call $K M$, et al. Complete physical map of the WAGR region of 11p13 localizes a candidate Wilms' tumor gene. Cell 1990;60:495-508.

3. Fischbach BV, Trout KL, Lewis J, Luis CA, Sika M. WAGR syndrome: a clinical review of 54 cases. Pediatrics 2005;116:984-8. 
4. Almind GJ, Brøndum-Nielsen K, Bangsgaard R, Baekgaard P, Grønskov K. 11p microdeletion including WT1 but not PAX6, presenting with cataract, mental retardation, genital abnormalities and seizures: a case report. Mol Cytogenet 2009;2:6.

5. Grønskov K, Olsen JH, Sand A, Pedersen W, Carlsen N, Bak Jylling AM, et al. Population-based risk estimates of Wilms tumor in sporadic aniridia. A comprehensive mutation screening procedure of PAX6 identifies 80\% of mutations in aniridia. Hum Genet 2001;109:11-8.

6. Min KS, Baek HJ, Han DK, You JH, Hwang TJ, Kwon DD, et al. Wilms' tumor, aniridia, genitourinary anomalies, and mental retardation (WAGR) syndrome: successful treatment of the first case with bilateral Wilms' tumors in Korea. Korean J Pediatr 2008;51:1355-8.

7. Xu S, Han JC, Morales A, Menzie CM, Williams K, Fan YS. Characterization of 11p14-p12 deletion in WAGR syndrome by array CGH for identifying genes contributing to mental retardation and autism. Cytogenet Genome Res 2008;122:181-7.

8. Breslow NE, Collins A, Ritchey ML, Grigoriev YA, Peterson SM, Green DM. End stage renal disease in patients with Wilms tumor: results from the National Wilms Tumor Study Group and the United States
Renal Data System. J Urol 2005;174:1972-5.

9. Pelletier J, Bruening W, Li FP, Haber DA, Glaser T, Housman DE. WT1 mutations contribute to abnormal genital system development and hereditary Wilms' tumour. Nature 1991;353:431-4.

10. Chao LY, Huff V, Strong LC, Saunders GF. Mutation in the PAX6 gene in twenty patients with aniridia. Hum Mutat 2000;15:332-9.

11. Pritchard-Jones K, Fleming S, Davidson D, Bickmore W, Porteous D,

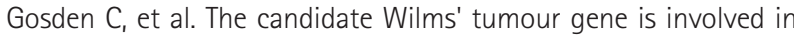
genitourinary development. Nature 1990;346:194-7.

12. Xu PX, Zhang $X$, Heaney $S$, Yoon A, Michelson AM, Maas RL. Regulation of Pax6 expression is conserved between mice and flies. Development 1999;126:383-95.

13. Pinna A, Carta A, Mannazzu MC, Dore S, Balata A, Carta F. WAGR syndrome with deletion of chromosome 11p11.2-13. J AAPOS 2004;8:396-7.

14. Han JC, Liu $\mathrm{QR}$, Jones $\mathrm{M}$, Levinn $\mathrm{RL}$, Menzie $\mathrm{CM}$, Jefferson-George $\mathrm{KS}$, et al. Brain-derived neurotrophic factor and obesity in the WAGR syndrome. N Engl J Med 2008;359:918-27. 